\title{
Kroppsopplevelse og selvmordsatferd
}

\author{
Ved Israel O rbach
}

\section{Hvilken rolle spiller kroppsopplevelser og kroppslige erfaringer for selvdestruktiv atferd?}

I denne artikkelen tas det utgangspunkt $i$ at prosesser som gjelder tidlig ivaretaking av barnet, spiller en sentral rolle i utvikling av selvdestruksjon gjennom endringer i kroppsopplevelse og negative holdninger til kroppen. Internalisering av tidlige negative omsorgsprosesser og negativ tilknytning kan føre til en forvrengt kroppsopplevelse og grunnleggende negative holdninger og følelser overfor egen kropp. Slike kroppsopplevelser og holdninger interagerer trolig med smerte, håpløshet og økende stress, og kan ende i selvdestruksjon.

$M$ ange faktorer har betydning for selvmord og selvmordsatferd. Vi kjenner minst 8 slike faktorer: mental tilstand, fenomenologisk tilstand, selvdestruktive prosesser, personlighetstrekk, stress, forhold som fremmer eller hemmer selvmordsatferd, bakgrunnsfaktorer og symptomatferd (O rbach 1997). H er vil jeg avgrense meg til å fokusere på faktorer som fremmer selvmordsatferd.

Faktorer som fremmer selvmord er ikke årsak til selvmord, men kan svekke ytre eller indre stengsler mot selvmordsatferd, og gjennom dette øke sannsynligheten for at en person velger selvmord i stedet for andre måter å mestre psykisk smerte på. Forhold som fremmer selvmordsatferd, omfatter det å oppleve selvmord i omgivel sene, våpentilgjengelighet, kulturelle normer, tiltrekning til død og dissosiative reaksjoner, slik som avspaltning fra og likegyldighet i forhold til egen kropp.

$H$ ypotesen som framsettes her, er at selvdestruktiv atferd kan føres til bake til tidlig fysisk tilknytning mellom barn og foreldre og til omsorgsprosesser. Tidlige positive omsorgsprosesser handler om tidlig samhandling mellom barn og for-

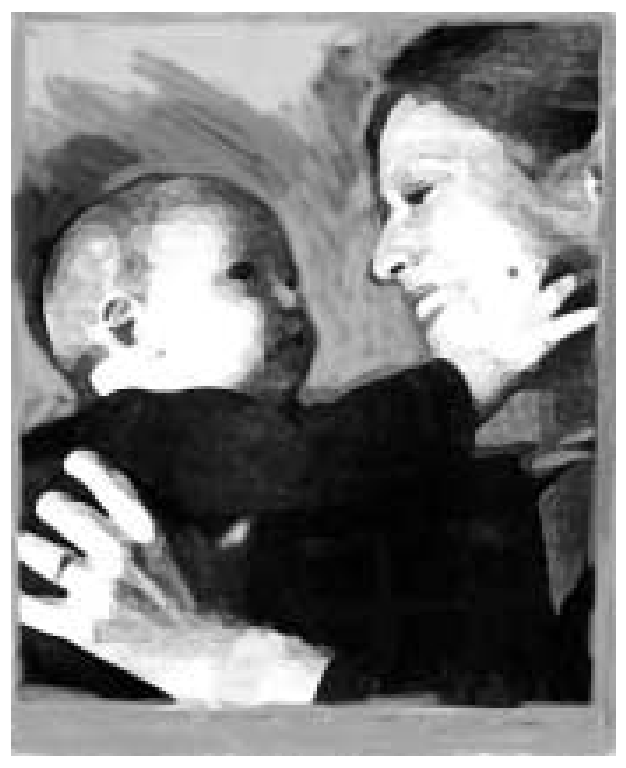

eldre, som er karakterisert ved en grunnleggen de fysisk og emosjonell oppmerksomhet overfor barnets behov for fysisk tilknytning; å bli berørt, innhyllet og holdt fysisk. Den ekstreme motsetningen til en slik positiv fysisk tilknytning er omsorgssvikt, mishandling, skade og traumer. Slike erfaringer kan seinere i livet fremme selvdestruktiv atferd (Briere 1989).

De to ekstreme formene for foreldretilknytning og omsorgsatferd blir internalisert av barnet som kroppslige hukommelsesspor, og resulterer etter hvert i stabile kroppsopplevelser og -holdninger ( Van der Velde 1985).

$M$ in grunnleggende påstand er at negativ erfaring med tidlige omsorgsprosesser er en viktig faktor $i$ utvikling av selvdestruktiv atferd, fordi dette etter hvert påvirker kvalitet og grad av personlig følelsesmessig involvering når det gjel der beskyttelse av egen kropp og bevaring av eget liv. $N$ egative omsorgsprosesser kan føre til forvrengt kroppsopplevelse og negative holdninger til kroppen. $\mathrm{N}$ år slike tilstander samvirker med andre prosesser, slik som sinne eller stress, kan de lette utviklingen av, men ikke være årsak til, selvdestruktiv atferd. I fravær av naturlige beskyttende faktorer kan selvmordsatferd lettere bli resultatet enn når selvbeskyttende holdninger til kroppen er til stede.

\section{Selvmord og kroppen - empiriske data}

Det foreligger empiriske data som viser forbindelse mellom tidlig omsorg, holdninger til kroppen og selvdestruksjon.

Salk (1985) fant i en postmortem-studie at tre faktorer skilte signifikant mellom ungdom som hadde tatt livet sitt, sammenlikna med to kontrollgrupper. I den første gruppa var det betydelig mer hyppig med dårlig kval itet på svan gerskapskontrollen, kronisk sjukdom hos mor og pustebesvær hos barnet etter fødselen. En måte å forstå dette på, som også Salk foreslo, er at medisinsk negl isjering under svangerskapet fremmer avvisning fra mor overfor barnet både før og etter at barnet er født.

G reen (1978) studerte hvilken virkning omsorgssvikt og overgrep har på selvdestruktiv atferd hos små barn. $\mathrm{H}$ an fant at selvdestruktiv atferd (biting, kutting, brenne seg selv, trekke ut hår, dunke hodet mot veggen og selvmordsforsøk) var langt hyppigere blant barn som hadde vært utsatt for omsorgssvikt og overgrep sammenlikna med normale barn. Lester (1991) rapporterte en sammenheng mellom fysiske overgrep eller fysisk straff $\mathrm{i}$ barnealder og seinere økt frekvens av selvmordsforsøk i ei gruppe personer i fengsel. Disse hadde også vært lenger i mors liv under svangerskapet og hadde i kortere periode fått bryst. En undersøkelse nylig utført av 0 rbach et al. (1995) påviser negative holdninger til kroppen hos suicidale og ikke-suicidale ungdommer. De suicidal e ungdommene opplevde større diskrepans mellom faktiske og ideelle kroppstrekk, mer negative føl elser i forhold til kroppen og større grad av kroppslig dissosiasjon. En rekke korrelasjoner viste at jo større suicidal tendens, desto høyere grad av dissosiasjon, og jo større diskrepans, desto sterkere negative følelser i forhold til kroppen.

I en annen studie ( 0 rbach \& Mikulincer 1996) fant vi at suicidale ungdommer hadde en tendens til i mindre grad å ta vare på kroppen og beskytte seg, sammenlikna med ikke-suicidale sykehuspasienter og ei normal kontrollgruppe. Samtidig viste den suicidale gruppa større grad av kroppslig anhedoni og mer depresjon sammenlikna med de to kontrollgruppene. De suicidale pasientene opplyste at de opplevde mindre grad av varme og større grad av overbeskyttelse fra mor. Ivaretakelse og beskyttelse av egen kropp var negativt korrelert med suicidale tendenser. 


\section{Fysisk smerte og suicidalitet}

Klarere empirisk støtte til den framsatte hypotesen fikk vi i flere studier som tok opp fysisk smertetoleranse hos suicidale ungdommer. Vi (O rbach et al. 1997) fant at suicidale ungdommer hadde en høyere smerteterskel og smertetoleranse sammenlikna med ei gruppe ikke-suicidale sykehuspasienter og ei normal kontrollgruppe. Videre korrelerte smertemålene signifikant med mål på suicidale tendenser, dissosiative tendenser og spesielt med håpløshet. Desto høyere suicidal tendens, dissosiering og håpløshet, desto høyere var toleransen for fysisk smerte.

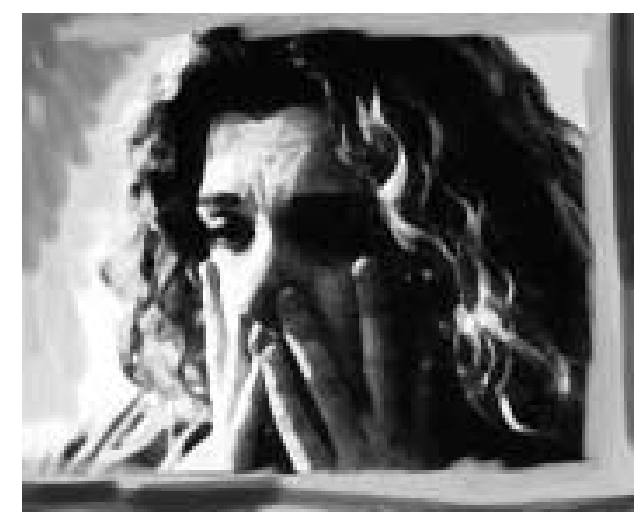

I en annen undersøkelse ( 0 rbach et al. 1996) fant vi at suicidale personer ikke bare tålte mer fysisk smerte sammenlikna med ei kontrollgruppe med personer som var skadet i ulykke. De to gruppene viste også forskjellig mønster i forholdet melIom fysisk smerte og indre stress. I den suicidale gruppa fant vi at jo mer negative følelser en person hadde til kroppen, jo mer vedkommende opplevde stress i livet og jo mer angst, desto høyere var også toleransen for fysisk smerte. I gruppa med personer som hadde vært utsatt for en ulykke, fant vi et omvendt forhold. Begge gruppene blei oppfatta å være under akutt stress (ulykke, selvmordsforsøk). I gruppa som hadde vært utsatt for en ulykke, så det ut til at økende indre stress (dvs. opplevd stress, dårlig kroppsbilde, depresjon), mobiliserte kroppens selvbevaringsk refter ved å senke responsterskelen for ytre skadelige stimuli (kroppslig smerte) for å unngå videre skade. I den suicidale gruppa førte økende indre stress til heving av responsterskelen for ytre stimulering, antakelig som en forsvarsmekanisme preget av avspaltning fra kroppen. Dette fører til at en lettere blir utsatt for videre skade og eventuelt sel vdestruksjon. Jeg mener at slike data gir noe støtte til antakelsen at suicidale personer opplever kroppen forskjellig fra ikke-suicidale.

\section{Selvmord og kroppen - teoretisk forståelse}

H vordan kan vi teoretisk forstå forholdet mellom kroppslig erfaring og suicidal atferd? Som Van der Velde vil jeg hevde at evnen til å være glad i sin egen kropp, fysisk egenomsorg og sel vbeskyttel se utvikles i spedbarnsalderen. Barnet forbinder de indre erfaringene av smerte, sult, tørst og fysisk vel være med ytre atferd, kroppsholdning og signaler fra omsorgsgiver (få mat, få skifta bleie, bli kjælt med), noe som igjen fører til endringer $i$ kroppsopplevelse. Foreldrenes omsorgsatferd blir imitert og internalisert av barnet, og danner grunnlaget for hvordan barnet vil beskytte seg og ta vare på seg selv i framtida. G jennom kjærlig foreldreomsorg Iærer barnet at hans eller hennes kropp er verdifull, verdt å el ske, og at livet er verdt å leve.

$\AA$ bli berørt er en livsopprettholdende kraft og et grunnleggende behov i tidlige utviklingsfaser. $\mathrm{H}$ arlow og medarbeidere (1959) viste empirisk behovet for sensorisk

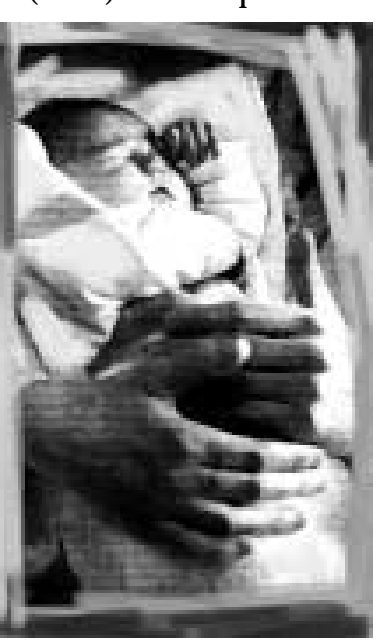

stimulering og kontaktsøking for å få fysisk trøst. Små apeunger foretrakk alltid mjuke tøymødre framfor harde ståltrådmødre som ga mat. A insworth et al. (1978) fant at spedbarn som blei holdt fysisk av mødrene over lengre perioder, blei følelsesmessig tryggere sammenlikna med spedbarn som blei holdt av utålmodige mødre. Fysisk kontakt mellom mor og barn viste seg å være livreddende for spedbarn med lav fødsel svekt da "Kengurumor-teknik- ken", som innebærer 24 timers hud-tilhud-kontakt, erstattet kuvøsebehan dling. En undersøkelse viste at denne metoden var like effektiv som kuvøsebehandling når det gjaldt alvorlig sjukdom i en oppføl gingsperiode på seks måneder (Scholz \& Samuels 1992). På samme måte fant Field et al. (1992) at barn og unge som var innlagt på sjukehus på grunn av psykiske problemer, slik som depresjon, atferdsforstyrrelser og suicidal atferd, hadde vært utsatt for fysisk mishandling eller lite berøring i tidlig barndom.

Spørsmålet som oppstår er: H vilke prosesser forbinder kroppsopplevelse med selvdestruktiv atferd? Maltsberger (1993) ser en sammenheng mellom forstyrrelser i selvrepresentasjoner, sammenblanding av selvet og andre, intenst sinne og selvmordsatferd. I følge hans syn består selvet av representasjoner (introjekter) av stabile indre erfaringer og erfaringer med foreldrefigurer. En kjærlig og omsorgsfull foreldretilnærming blir en integrerende kraft som gradvis organiserer de ulike representasjonene inn i et sammenhengende selv.

Introjekter av personer, f.eks foreldre, som barnet hater kan ofte anta kroppslige representasjoner, som om den hatede personen metaforisk blir representert av kroppen. Denne prosessen er motivert av et ubevisst ønske om å eliminere eller ødelegge foreldrefiguren.

Furman (1984) mener at en finner utgangspunktet for suicidal atferd $i$ tidlige sadomasochistiske forhold til omsorgsgiver. Introjisering av foreldrenes sadistiske tendenser kombinert med barnets egen aggresjon kan føre til en forvrengt oppfatning og erfaring av smerte og nytelse. Et slikt barn kan forveksle smerte og nytelse, og kan bruke sel vpåført smerte som en måte å redusere trusselen om avstraffelse på.

Jeg vil foreslå dissosiering som en annen mulig prosess som forbinder kroppsopplevelse og selvmordsatferd (se O rbach 1994). K roppslig dissosiering antas å oppstå i forbindelse med uutholdelige omstendigheter tidlig i livet, slik som avvisning, et sadomasochistisk forhold eller fysiske overgrep/misbruk. Slike erfaringer kan gi opphav til dissosiative prosesser som 
forsvarsmekanisme. Etter hvert kan dissosiasjonen arte seg som avspaltning fra kroppen, nummenhet, likegyldighet i forhold til kroppen, og uføl somhet overfor fysisk smerte. Dissosiering eller kroppslig avspaltning innebærer en fysiologisk prosess som høyner terskelen for kroppslige stimuli, som forsvar mot uventa traumer eller for å bringe påkjenninger til opphør. Dissosiering og likegyldighet overfor fysisk smerte kan øke risikoen for suicidal atferd under øken de ytre eller indre stress, særlig når en person utvikler sterke følelser av håpløshet og depresjon. Distansering, apati, håpløshet og negative følelser til kroppen kan svekke motstandskraften mot selvmord etter hvert som en person opplever at han eller hun har mindre å tape når det gjelder å ha glede av sin kropp, ved å gjøre selvmord.

\section{Et forsøk på integrering}

A lle disse begrepsformul eringene innebærer en sammenheng mellom forstyrra omsorg for barnet, forvrengt kroppsopplevelse, holdninger til kroppen og selvdestruktiv atferd. G jennom begrepsformuleringene foreslås det at foreldrenes holdninger til barnet, slik dette avspeiler seg i deres omsorgsatferd, blir internal isert av barnet som barnets negative holdninger til egen kropp. På samme måte kan tidlig omsorgsatferd påvirke den måten barnet, og seinere den voksne, opplever sin egen kropp på. Den måten en person opplever egen kropp på, kan også påvirke hans/

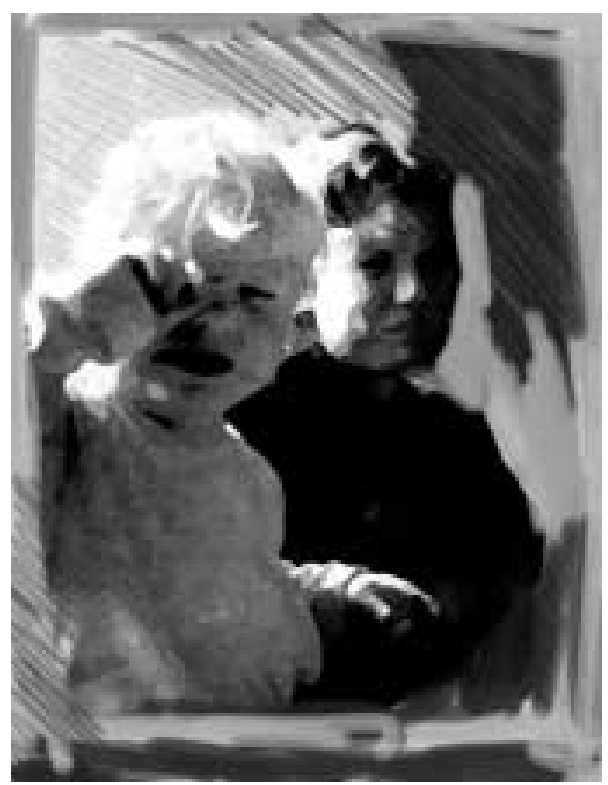

hennes holdning til kroppen; dårlig kroppsbilde, neglisjering av kroppen, likegyldighet til eller avvisning av kroppen. A lle begrepsformuleringene betrakter også den forvrengte kroppsopplevelsen som en defensiv tilbaketrekning fra en smertefull virkelighet. U nder al vorlig stress og opplevel se av håpløshet kan endringer og fordreininger i kroppsopplevelse interagere med allerede eksisteren de negative holdninger og kroppserfaringer, og bidra til selvdestruktiv atferd.

$H$ ypotesen som framsettes her, innebærer ikke at kroppslige prosesser i seg selv er årsak til selvmord. Selvmord kan ikke forstås uten at det relateres til mental smerte. D et er mental smerte som setter den suicidale prosessen i bevegelse, men visse kroppslige erfaringer og holdninger til kroppen kan lette og påskynde selvdestruksjon. N år følelser, slik som håpløshet, kombineres med en eller annen form for endra kroppsopplevelse eller -holdning som beskrevet her, kan suicidalitet lettere omsettes til handling. Jeg tror at en økt forståel se av kroppens betydning for suicidal atferd kan være nyttig for å utvikle nye og bedre strategier i behandling og forebygging av suicidal atferd. Selv om kroppslige prosesser bare delvis forklarer utviklingen av suicidal atferd, kan økt forståelse av kroppens rolle når det gjelder selvmord, som M altsberger (1993) også sier, bli en av de viktigste skritt på veien til studiet av og muligens også for behandlingen av selvdestruktiv atferd.

\section{(A rtikkelen er oversatt av Ingebjørg H estetun.)}

\section{Litteratur}

A insworth M DS, Blehar M C, W aters E, W all S. Patterns of attachment: a psychological study of the Stranger situation. Hillsdale, N J: Erlbaum, 1978.

Briere J. T herapy for adults molested as children. N ew York: Springer, 1989.

Field T, M orrow C, Valdeon C, Larson S, Kuhn $C$, Schanberg $S$. M assage reduces anxiety in child and adolescent psychiatric patients. Journal of the A merican A cademy of C hild and $A$ dolescent Psychiatry 1992; 81: 125-31.

Furman $\mathrm{E}$. C hildren's patterns in mourning the death of a loved one. I W ass H, C orr, CA . (eds.): $C$ hildhood and death. Series in death education, aging, and health care. W ashington, DC : H emisphere Publishing, 1984: 185-203
G reen $A H$. Self-destructive behavior in battered children. A merican Journal of Psychiatry 1978; 135: $579-81$.

H arl ow HF, Zimmerman RR. A ffectional responses in the infant monkey. Science 1959; 130: 421-32

Lester D. Physical abuse and physical punishment as precursers of suicidal behavior. Stress M edicine 1991; 7: 255-71.

$M$ altsberger JT. C onfusion of the body, the self and others in suicidal states. I: Leenaars A A red. Suicidology: essays in honor of Edwin $S$ Shneidman. N orthvale, NJ: Jason A ronson, 1993.

O rbach I. Dissociation, physical pain, and suicide: a hypothesis. Suicide and Life-T hreateningBehavior 1994; 24:68-79.

0 rbach I. A taxonomy of factors related to suicidal behavior. Clinical Psychology: Science and Practice 1997; 4: 208-24.

O rbach I, Lotem-Peleg M, Kedem P. A ttitudes toward the body in suicidal, depressed, and normal adolescents. Suicide and Life-T hreateningBehavior 1995; 25(2): 211-221

O rbach I, M ikulincer M. B ody care, dissociation, and physical anhedonia in suicidal youngsters. Ramat-G an, Israel: Department of Psychology, Bar-Ilan U niversity, 1996.

O rbach I, M ikulincer $M$, King $R$, C ohen $D$, Stein D. Thresholds and tolerance of physical pain in suicidal and nonsuicidal adolescents. Journal of Consulting and Clinical Psychology 1997; 64: 646-52.

Orbach I, Stein D, Palgi $Y, A$ sherov J, H ar-Even $D$, Elizur A. Perception of physical pain in accident and suicide attempt patients: selfpreservation vs. self-destruction. Journal of Psychiatric Research 1996; 30: 307-20.

Salk L. R elationship of maternal and prenatal condition to eventual adolescent suicide. Lancet 1985; 16: 624-7.

Scholz K, Samuels C. N eonatal bathing and massage interventions with fathers, behavioral effects 12 weeks after birth of the first baby: the Sunraysia A ustralia Intervention Project. International Journal of Behavioral Development 1992; 15: 67-81.

Van der Velde CD. B ody image of one's self and of others: developmental and clinical significance. A merican Journal of Psychiatry 1985; 142: 527-37.

Israel O rbach, PhD, er professor i psykologi ved Bar-Ilan-U niversitetet i I srael.

$\mathrm{H}$ an arbeider med forskning og behandling av selvmordsatferd hos barn, ungdom og voksne, og har gitt ut flere bøker og ca. 100 artikler.

$\mathrm{H}$ an har grunnlagt "Israel A ssociation for Suicide Prevention", og er nå dekan for "G raduate Studies" (master's level) ved Bar-Ilan. 